\title{
A New Framework for Music Education Knowledge and Skill
}

J. Si Millican

http://online..sagepub.com

\author{
University of Oklahoma, Norman
}

\begin{abstract}
This study investigates perceptions of secondary school band and orchestra teachers regarding the relative importance of knowledge and skill categories to professional success, using a framework modeled after Schulman (1986, 1987). Band and orchestra teachers in secondary schools $(N=214)$ complete an anonymous, online survey ranking the relative importance of various knowledge and skill categories. Participants rank pedagogical content knowledge, content knowledge, and general pedagogical knowledge highest. There are no significant differences in the rankings of the categories among various subgroups at the $p<.05$ level. Results confirm the applicability of Schulman's model to music education. This framework has implications for undergraduate, graduate, and continuing professional education. Analysis of categories' interaction provides insight into effective classroom instruction.
\end{abstract}

Keywords: pedagogical content knowledge; curriculum; teacher preparation; frameworks; general pedagogical knowledge; content knowledge

$\mathrm{M}$ usic teacher educators must possess a thorough understanding of the skills and knowledge that classroom teachers use in their daily work. The knowledge and skills necessary to provide effective instruction to students includes a wide variety of factual musical knowledge as well as performance skill on various instruments. Knowledge of students, general teaching skills, administrative skills, and an awareness of the ways most people learn most efficiently are essential to educators' success (Darling-Hammond, 2006). This complex combination of skills and knowledge operates in a distinct school and community climate that affects the selection and delivery of content.

How do higher education professionals in music education programs break apart the complex knowledge and skill base of effective teachers and develop graduates who are sufficiently prepared to work with students in public schools? Music teacher educators need a comprehensive knowledge base-a compilation of "the entire

This study presents partial findings of the author's doctoral dissertation while at the University of Oklahoma. The author wishes to acknowledge the support and assistance of Dr. Nancy H. Barry and Dr. Michael A. Raiber. Correspondence concerning this article should be addressed to Si Millican, Institute for Music Research, University of Texas at San Antonio, One UTSA Circle, San Antonio, TX 78249; e-mail: si.millican@utsa.edu. 
repertoire of skills, information, attitudes, etc., that teachers need to carry out their classroom responsibilities" (Valli \& Tom, 1988, p. 5).

Although a great deal of data have been generated related to the technical knowledge and skills practitioners and education faculty find essential, there has yet to be a comprehensive framework into which procedural and declarative knowledge can be placed to reflect the complex nature of daily life in the classroom (Leonhard, 1985). Although much research has gone into individual components of effective teaching, "only the vaguest outlines of a knowledge base framework" exists in the research literature to organize the skill set necessary for teacher success (Valli \& Tom, 1988, p. 6).

Schulman $(1986,1987)$ proposed a framework for general teacher education that reflected how effective teachers combine various knowledge and skill components. According to Schulman, the missing aspect in all of these compilations of knowledge and skill is an organizational framework that arranges teaching elements in a way that reflects how these skills are applied in the classroom. He categorizes the knowledge base for teachers into broad and interrelated areas, and his framework can be used to help organize the many areas of knowledge and skill that previous research has shown to contribute to successful teaching in instrumental music:

Content knowledge: Items related to factual knowledge of a particular discipline. For the music educator, this area would include items such as performance skills on primary and secondary instruments, music theory, analysis, arranging, music history, instrument fingerings, repair, and conducting skills.

General pedagogical knowledge: Knowledge related to general teaching and presentation skills. These skills are not subject specific and include classroom management, presentation, and communication skills, as well as the establishment of class routines.

Curriculum knowledge: Knowledge of specific techniques and commonly adopted schools of thought related to delivery of instruction, including method books, literature selection, and specific schools of technique. Knowledge of the sequences related to how people learn music most efficiently is also included in this category.

Knowledge of learners and their characteristics: Skill and knowledge related to the awareness of the social, physical, and psychological development levels of students and how these characteristics influence decisions made in the classroom. Knowledge of learning styles, entry points, and diversities of all kinds are characteristic components related to this category.

Pedagogical content knowledge: "the blending of content and pedagogy into an understanding of how particular topics, problems, or issues are organized, represented, and adapted to the diverse interests and abilities of learners, and presented for instruction. Pedagogical content knowledge is the category most likely to distinguish the understanding of the content specialist from that of the pedagogue" (Schulman, 1987, p. 8).

In the music education realm, pedagogical content knowledge separates the professional musician from the professional music educator; teachers must possess a different perspective of musical knowledge to combine their music skills and 


\section{Figure 1 \\ Modified Schulman (1986, 1987) Knowledge Base Framework, Viewed From Above}

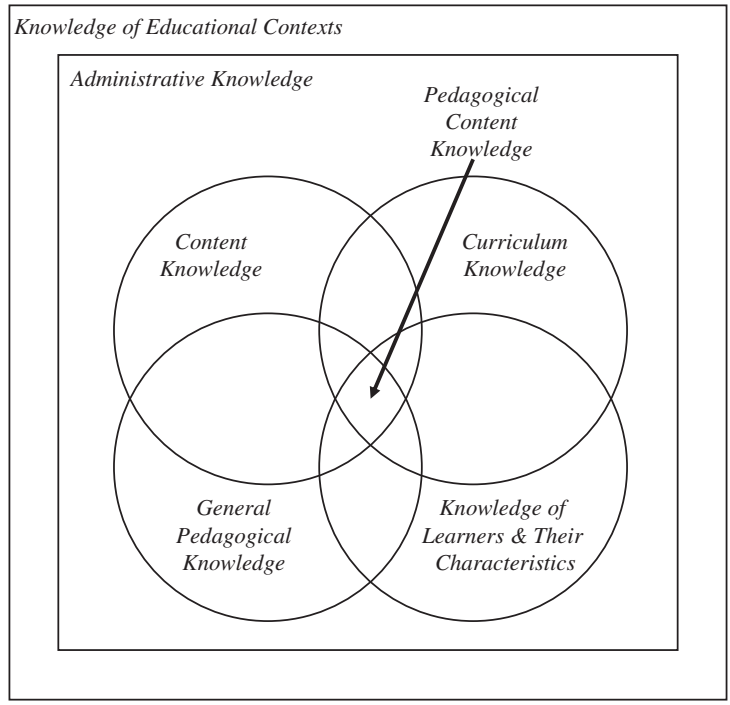

knowledge with a working knowledge of learners and their prior experiences to communicate musical concepts most effectively.

Knowledge of educational contexts: The awareness of the special characteristics of the school, district, community, and national expectations and customs, as they relate to the delivery of instruction. Working with parents, administrators, colleagues, and the community are included in this category.

For instrumental music educators in the public school environment, a final category not specifically mentioned by Schulman - administrative knowledge-is necessary to include items dealing with the management of financial, travel, inventory, and student information.

The interrelationships among these categories can be visualized in Figure 1 (for other visualizations of Schulman's framework, see Veal \& MaKinster, 1999). The areas of content knowledge, general pedagogical knowledge, curriculum knowledge, and knowledge of learners and their characteristics overlap to create an area in the center of the chart that represents pedagogical content knowledge. This arrangement acknowledges the interrelated nature of these areas and illustrates how pedagogical content knowledge functions as a combination of the previously listed areas of 
Figure 2

\section{Modified Schulman (1986, 1987) Knowledge Base Framework, Viewed From the Front}

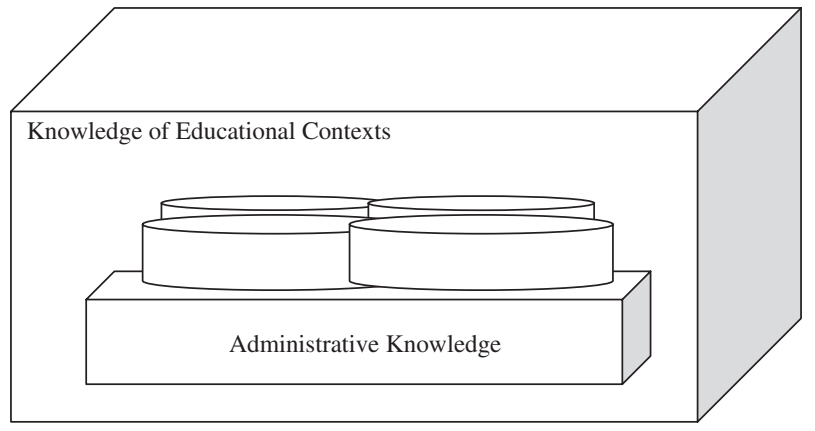

knowledge. Administrative knowledge is represented in Figure 1 as the foundation that supports the workings of the five overlapping pedagogical areas. Figure 2 illustrates the support function that administrative knowledge serves; and although administrative knowledge is not directly related to classroom instruction, it acts as a support platform on which the other five areas rest. Knowledge of educational contexts serves as an all-encompassing box in which the five pedagogical areas and administrative knowledge rest.

Although Schulman's $(1986,1987)$ work has been increasingly incorporated into teacher certification guidelines and accreditation procedures (Interstate New Teacher Assessment and Support Consortium, 1992; National Association of Schools of Music, 2005; National Board for Professional Teaching Standards, 2001; National Council for Accreditation of Teacher Education, 2006), his work is cited as an area into which more music education research is needed (Niermen, Zeichner, \& Hobbel, 2002).

Few studies have investigated the applicability of the Schulman framework in the music education field (e.g., Ballantyne \& Packer, 2004). Is this framework a useful representation of how in-service music teachers integrate their knowledge and skills? If so, what are the perceptions of practicing music teachers as to the relative importance of the various categories?

\section{Method}

This study investigated the perceptions of secondary band and orchestra teachers regarding the relative importance of the categories of knowledge and skill to professional success. Two research questions were developed: 
1. Which knowledge and skill categories are thought to be most important to professional success by secondary band and orchestra teachers?

2. How do variables related to the respondents' teaching assignments and educational backgrounds interact with the individual rankings of knowledge and skill categories?

Participants for the study were drawn from a random sample of band and orchestra teachers from public secondary schools across the United States, using data from the National Center for Education Statistics (2004). Potential participants were invited to join the study through e-mail and postal invitations followed by one set of reminder postcards and e-mail messages. In an effort to improve response rates, a personalized invitation to participate was generated. An attempt was made to find the names and e-mail addresses of the band and/or orchestra directors from each of the schools that were randomly selected for possible inclusion. Names and e-mail addresses for potential respondents were gathered by locating the public Web site for each randomly selected school.

The primary data collection instrument for this study was an online, anonymous questionnaire. Using a paired comparison technique, respondents were asked to rank the importance of each of the seven broad categories: content knowledge, general pedagogical knowledge, curriculum knowledge, pedagogical content knowledge, knowledge of learners and their characteristics, knowledge of educational contexts, and administrative knowledge. Researchers in the social sciences have used the paired comparison technique when lists of items that can only be ranked subjectively are analyzed (David, 1988; Nishisato, 2007). In the paired comparison method, each item is presented in comparison with every other item one at a time (e.g., content knowledge vs. general pedagogical knowledge). Respondents are asked which of the two items presented is more important. By comparing each item with every other item in a list, an overall rank of the entire list of items can be derived for each individual. To achieve the ranking of the categories among all respondents, the median scores and the standard error are calculated for each category. In this study, a brief definition of each category was presented to participants below each paired comparison question.

Participants were also asked to provide information regarding teaching assignments and educational backgrounds. This information was analyzed to show potential relationships between these variables and the individual rankings of the categories. In the final portion of the survey, participants were given the opportunity to provide additional comments.

Chi-square tests of independence were performed to compare the respondents' rankings of the individual categories with the following variables: (a) subject area taught, (b) grade levels taught, (c) enrollment size of the instructor's school, (d) geographic location within the United States of the respondent's school, (e) number of full-time instrumental music teachers assigned to the respondent's primary campus, (f) amount of teaching experience in his or her primary subject area, (g) size of the 
Table 1

Rank Order of the Seven Modified Schulman Categories

\begin{tabular}{lccc}
\hline Category & Grouped Median & Standard Error of Mean & Range \\
\hline Pedagogical content knowledge & 3.78 & .17 & 10 \\
Content knowledge & 2.94 & .18 & 10 \\
General pedagogical knowledge & 1.93 & .20 & 10 \\
Curriculum knowledge & -0.47 & .22 & 12 \\
Knowledge of learners & -0.75 & .22 & 12 \\
Knowledge of educational contexts & -3.35 & .18 & 12 \\
Administrative knowledge & -4.73 & .17 & 12 \\
\hline
\end{tabular}

undergraduate institution from which the teacher received his or her degree, and (h) amount of early field experience that was required in conjunction with their undergraduate degree programs.

A pilot study using volunteers from a listing of secondary instrumental instructors from one geographic region of a southwestern state $(N=60)$ helped establish validity and reliability of the main survey instrument. The main study examined the opinions of a randomly selected sample of secondary band and orchestra teachers from across the United States $(N=214)$.

\section{Results}

Analyzing the paired comparison responses $(N=214)$ produced the rank of the categories in relationship to each other (see Table 1). The paired comparison technique produces a rank-order score derived by calculating the number of times an item is favored to another item minus the total number of times another item is preferred over the original item (David, 1988; Nishisato, 2007). To achieve the ranking of the categories among all respondents, the median scores and the standard error were calculated for each category. The grouped median was derived from the power table produced during the analysis of the paired comparison rankings. This power table represents the number of times a category within each pair was selected as more important minus the number of times other categories were selected as more important. Categories with higher scores indicate a greater preference for that category when compared to each of the other categories. Categories with lower scores indicate a preference for other categories. The standard error of mean indicates the degree of agreement among the respondents. Lower numbers indicate greater agreement. The most preferred categories, pedagogical content knowledge and content knowledge, had lower standard error scores and indicate a greater agreement among respondents. The least preferred categories, knowledge of educational contexts and administrative knowledge, also have relatively low standard error scores that also indicate a greater agreement among 
Figure 3

\section{Relationship of the Overall Rankings of the Seven Modified Schulman Categories}

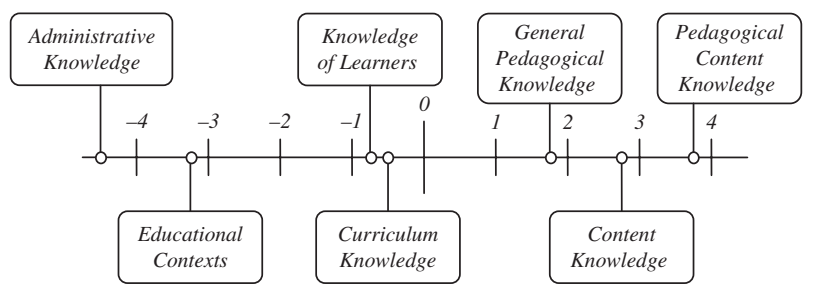

respondents. Figure 3 is a representation of the preference of the overall group plotted horizontally to show the strength and relationship of the preferences.

Analysis of the chi-square tests of independence showed no significant interaction between the rankings of these seven areas and the variables related to respondents' teaching assignment and educational background at the $p<.05$ level. These variables included teaching assignment, grade level, region within the United States, staff size, teaching experience, undergraduate institution size, and length of early field experience.

The rankings of these seven areas were nearly identical to the results from the pilot study. In both studies, the top three areas-pedagogical content knowledge, content knowledge, and general pedagogical knowledge-were all ranked markedly higher than the other four areas. Pedagogical content knowledge was the highest ranked category in both the pilot study and the main study.

\section{Discussion}

\section{The Schulman Framework and its Application to Music Education}

Instrumental music teachers in this study were consistently able to rank the knowledge and skill components of a knowledge base for music teaching as shown by the widespread agreement in rankings of the seven modified Schulman (1986, 1987) categories. The separation of pedagogical content knowledge, content knowl-

edge, and general pedagogical knowledge, from the remainder of the seven areas was remarkably consistent across every demographic variable in the primary study. The results of this study indicate that the Schulman framework is both reliable and 
valid as an organizational representation for the skills and knowledge that music teachers in public schools use on a daily basis in their classrooms. Although many of the respondents complained about being "forced" to make paired comparison choices, their responses were remarkably consistent. This consistency across a wide range of variables and the similarity of the rankings of these categories in both the pilot and main study was an unexpected confirmation of the applicability of the Schulman model to instrumental music education.

The way in which the respondents' rankings of the Schulman $(1986,1987)$ categories clustered helped confirm the applicability of the structure of the framework. In both the pilot study and the main study, the three highest ranked categoriespedagogical content knowledge, content knowledge, and general pedagogical knowledge-clustered at the top of the rating scale (see Figure 3). These three categories were preferred more often than the other four categories by an overwhelming majority of the respondents. This finding is similar to those of Ballantyne and Packer (2004) in which pedagogical content knowledge was rated as the most valued category of knowledge and skill among instrumental music teachers.

The relationship of the rankings of pedagogical content knowledge and content knowledge reflects their interrelatedness. The fact that pedagogical content knowledge was ranked consistently at the top of the rating scale reflects the value of that category by a diverse sample of music teachers. The ranking of this skill, which is itself representative of the complex delivery process of musical concepts, helps to solidify the notion that knowledge of musical facts and performance ability on musical instruments are not sufficient in themselves to guarantee teaching success (Berliner, 1986; Clifford \& Guthrie, 1988; Davidson, Moore, Sloboda, \& Howe, 1998; Good, 1990; Greher \& Tobin, 2006; Kennedy, 1987). The ranking of content knowledge near the top of the scale helps reinforce the notion that performance ability and factual knowledge are key components to a successful music teacher education. That music educators value both performance skills and factual knowledge may be viewed as supportive of Elliott's (1995) praxial philosophy of music education, in which actual music making is the key component of the transfer and acquisition of musical knowledge.

The results also appear to confirm the relationship of the two lowest ranked areas-administrative knowledge and knowledge of educational contexts- to the entire model (see Figure 2). Although not at the top of the importance list, respondents commented that administrative knowledge was an important element in their professional success. In relationship to the rankings of the other categories, the relatively low ranking of administrative knowledge may be viewed as a foundation on which the other knowledge and skills rest.

Knowledge of educational contexts was ranked near the bottom as well but serves as an important frame for decisions made in each of the other categories. Survey respondents clearly separated these two categories from the other five areas, and many of their written comments addressed the underlying fundamental importance 
of these items, even though they may have been ranked lower in comparison with the other areas. One respondent wrote, "Administrative tasks and communication with the community are vital to my job, and yet I found myself not ranking it as high as the teaching things."

It appears that these practitioners recognize that content comprehension and pedagogical skill, although important, are only effective when they are combined in such a way as to connect with their students' prior learning and preconceptions of musical concepts. This pedagogical content knowledge is the primary way in which we distinguish the musician from the music educator. Practitioners value the successful balance of all seven Schulman areas; this notion was confirmed repeatedly by the majority of the comments that directors made in the survey. As one respondent wrote, "It is frustrating having to rate things that are ALL important. Which is more important in running a race, your right foot or your left foot?" Another added, "Music teachers that are very successful are not one dimensional in any manner."

In this respect, it is important to note that the lower ranked categories were not considered "unimportant" by survey participants; these items were merely chosen less often than the other categories. Many of the directors expressed frustration when asked to choose between two categories they viewed as equally important. One director spoke to the complexity of the teaching act as the primary reason ranking items in the survey was difficult:

It is very hard to place any of these things above the others, because it is a unique balance of all of the skills mentioned in this survey that make for effective teaching and working in a school environment. The relative importance of these skills vary from day to day, and even class to class depending on what is happening in the class, with the students, with the teacher, and even with the weather. It is the ability to use all of the skills mentioned here in a flexible way to be a truly skilled educator.

This statement confirms the complications associated with classifying elements encountered in the complex environment of classrooms (Bresler, 1993). Some directors pointed out that there was a difference in the day-to-day importance of an item versus situational importance. As one director commented, "The "daily' importance does not necessarily reflect overall importance."

\section{Implications for Music Teacher Education Programs}

Music education program design, as well as individual courses and experiences within the overall program, may benefit from a careful examination of how teachers rated the Schulman categories. The practitioner ratings of the Schulman categories, specifically the fact that both content knowledge and pedagogical content knowledge clustered consistently at the top of the importance ratings, reinforce the belief that content knowledge is important but not sufficient to guarantee effective teaching (Davidson et al., 1998). 
The high regard with which participants held pedagogical content knowledge helps reinforce the belief that the acquisition of content knowledge is most effective when music teacher educators help provide ample opportunities for preservice teachers to contextualize their knowledge through observation and interaction with authentic experiences related to public school teaching (Paul, 1998). Nagle (2004) writes that "the intersection of beliefs and participation" is the vehicle that moves teachers from possession of content knowledge to acquisition of pedagogical content knowledge (p. 156). These intersections can be developed in guided early field experiences (Wolfgang, 1990), laboratory classes that include microteaching opportunities (Butler, 2001; Miller, 2001; Paul, 1998), case studies (Conway, 1997, 1999; Lind, 2001), and ample opportunities to reflect on the effectiveness of teaching and planning activities (Barry, 1996). This relationship confirms the work of Segal (2004) and Darling-Hammond (2006) in recognizing that the successful blend of content and pedagogy is the hallmark of powerful teacher education programs.

An approach based on the acquisition and development of pedagogical content knowledge may also provide a useful framework for in-service teacher training and graduate-level work in music education. Monet (2006) presented research suggesting that in-service teacher development is best approached through recognition not of the content itself but the way that content is best presented to students. Anecdotal evidence suggests that although music teachers may desire the acquisition of additional musical content during graduate study, they most often seek the skills to become better communicators of the musical concepts and skills that their students need.

Results of this study confirm the applicability of Schulman's $(1986,1987)$ model to the knowledge and skills used by music educators. By more scientifically defining the elements of how expert teachers use this framework and how it is developed by preservice and in-service teachers, more effective undergraduate, graduate, and continuing education programs could be developed. This model, especially considering its implications related to teacher self-efficacy, may be an important framework to consider when efforts are made to improve teaching effectiveness and promote longevity and persistence in teaching careers.

\section{References}

Ballantyne, J., \& Packer, J. (2004). Effectiveness of preservice music teacher education programs: Perceptions of early-career music teachers. Music Education Research, 6(3), 299-312.

Barry, N. H. (1996). Promoting reflective practice in an elementary music methods course. Journal of Music Teacher Education, 5(2), 6-13.

Berliner, D. C. (1986). In pursuit of the expert pedagogue. Educational Researcher, 15(7), 5-13.

Bresler, L. (1993). Teacher knowledge in music education. Bulletin of the Council for Research in Music Education, 118, 1-20.

Butler, A. (2001). Preservice music teachers' conceptions of teaching effectiveness, microteaching experiences, and teaching performance. Journal of Research in Music Education, 49(3), 258-272. 
Clifford, G. J. \&. Guthrie, J. W. (1988). Ed school: A brieffor professional education. Chicago: University of Chicago Press.

Conway, C. M. (1997). The development of a casebook for use in instrumental music education methods courses (Doctoral dissertation, Columbia University Teachers College). Dissertation Abstracts International, 58(9), 3452A.

Conway, C. M. (1999). The development of teaching cases for instrumental music methods courses. Journal of Research in Music Education, 47(4), 343-356.

Darling-Hammond, L. (2006). Powerful teacher education: Lessons from exemplary programs. San Francisco: Jossey-Bass.

David, H. A. (1988). The method of paired comparisons. London: Charles Griffin \& Company.

Davidson, J. W., Moore, D. G., Sloboda, J. A., \& Howe, M. J. (1998). Characteristics of music teachers and the progress of young instrumentalists. Journal of Research in Music Education, 46(1), 141-160.

Elliott, D. J. (1995). Music matters: A new philosophy of music education. New York: Oxford University Press.

Good, T. L. (1990). Building the knowledge base of teaching. In D. D. Dill (Ed.), What teachers need to know (pp. 17-75). San Francisco: Jossey-Bass.

Greher, G. R., \& Tobin, R. N. (2006). Taking the long view toward music teacher preparation: The rationale for a dual-degree program. Music Educators Journal, 92(5), 50-55.

Hoffman, M. E. (1988). Teacher competence and the balanced music curriculum. Reston, VA: Music Educators National Conference.

Interstate New Teacher Assessment and Support Consortium. (1992). Model standards for beginning teacher licensing, assessment and development: A resource for state dialogue. Washington, DC: Author.

Kennedy, M. M. (1987). Inexact sciences: Professional education and the development of expertise. East Lansing: Michigan State University, National Center for Research on Teacher Education.

Leonhard, C. (1985). Toward reform in music teacher education. Council for Research in Music Education Bulletin, 81, 10-17.

Lind, V. R. (2001). Designing case studies for use in teacher education. Journal of Music Teacher Education, 10(2), 7-14.

Miller, M. L. (2001). Enriching pedagogical content knowledge of prospective chemistry teachers: How can the science methods course help? (Doctoral dissertation, Purdue University) Dissertation Abstracts International, 63(12), 4280A.

Monet, J. A. (2006). Examining topic-specific PCK as a conceptual framework for in-service teacher professional development in earth science (Doctoral dissertation, Rutgers, The State University of New Jersey, New Brunswick). Dissertation Abstracts International, 67, 10.

Nagle, J. F. (2004). Getting their sea legs: Prospective teachers navigating through a teacher education program (Doctoral dissertation, University of California, Berkeley). Dissertation Abstracts International, 66(2), 557A.

National Association of Schools of Music. (2005). Handbook 2005-2006. Reston, VA: Author.

National Board for Professional Teaching Standards. (2001). NBPTS music standards for teachers of students 3-18+ [electronic version]. Retrieved November 17, 2006, from http://www.nbpts.org/ for_candidates/certificate_areas? ID $=14 \& \mathrm{x}=36 \& \mathrm{y}=10$

National Center for Education Statistics. (2004). Search for public schools. Retrieved January 5, 2007, from http://nces.ed.gov/ccd/schoolsearch/

National Council for Accreditation of Teacher Education. (2006). Professional standards for the accreditation of schools, colleges, and departments of education. Washington, DC: Author.

Niermen, G. E., Zeichner, K., \& Hobbel, N. (2002). Changing concepts of teacher education. In R. Colwell \& C. Richardson (Eds.), The new handbook of research on music teaching and learning (pp. 818-839). Oxford, UK: Oxford University Press.

Nishisato, S. (2007). Multidimensional nonlinear descriptive analysis. Boca Raton, FL: Chapman \& Hall. 
Paul, S. J. (1998). The effects of peer teaching experiences on the professional role development of undergraduate instrumental music education majors. Bulletin of the Council for Research in Music Education, 137, 73-92.

Schulman, L. S. (1986). Those who understand: Knowledge growth in teaching. Educational Researcher, 15(2), 4-14.

Schulman, L. S. (1987). Knowledge and teaching: Foundations of the new reform. Harvard Educational Review, 57(1), 1-22.

Segal, A. (2004). Revisiting pedagogical content knowledge: The pedagogy of content and the content of pedagogy. Teaching \& Teacher Education: An International Journal of Research and Studies, 20(5), 489-504.

Valli, L., \& Tom, A. R. (1988). How adequate are the knowledge base frameworks in teacher education? Journal of Teacher Education, 39(5), 5-12.

Veal, W. R., \& MaKinster, J. G. (1999). Pedagogical content knowledge taxonomies [electronic version]. Electronic Journal of Science Education, 3(4). Retrieved December 3, 2006, from http://wolfweb.unr .edu/homepage/crowther/ejse/vealmak.html

Wolfgang, R. (1990). Early field experience in music education: A study of teacher role socialization (Doctoral dissertation, University of Oregon, 1990) Dissertation Abstracts International, 52(01), 137A. 